\title{
Preparation and Performance of the Hyperbranched Polyamine as an Effective Shale Inhibitor for Water-Based Drilling Fluid
}

\author{
Yuan Liu' ${ }^{1}$, Xiao Luo' ${ }^{*}$, Jianbo Wang², Zhiqi Zhou ${ }^{2}$, Yue Luo', Yang Bai ${ }^{3}$ \\ ${ }^{1}$ School of Chemistry \& Environmental Engineering, Yangtze University, Jingzhou, China \\ ${ }^{2}$ Oilfield Chemical Division of China Oilfield Services Co., Ltd., Zhanjiang, China \\ ${ }^{3}$ State Key Laboratory of Oil and Gas Reservoir Geology and Exploitation, School of Oil \& Natural Gas Engineering, \\ Southwest Petroleum University, Chengdu, China \\ Email: *cdlx19850711@163.com
}

How to cite this paper: Liu, Y., Luo, X., Wang, J.B., Zhou, Z.Q., Luo, Y. and Bai, Y. (2021) Preparation and Performance of the Hyperbranched Polyamine as an Effective Shale Inhibitor for Water-Based Drilling Fluid. Open Journal of Yangtze Gas and Oil, 6, 161-174.

https://doi.org/10.4236/ojogas.2021.64014

Received: September 26, 2021

Accepted: October 23, 2021

Published: October 26, 2021

Copyright $\odot 2021$ by author(s) and Scientific Research Publishing Inc. This work is licensed under the Creative Commons Attribution International License (CC BY 4.0).

http://creativecommons.org/licenses/by/4.0/ (c) (i) Open Access

\begin{abstract}
Seeking effective solutions to control and mitigate the interaction between drilling fluids and clay formations has been a challenge for many years, and various shale inhibitors have shown excellent results in problematic shale formations around the world. Herein, the hyperbranched polyamine (HBPA) inhibitor with a higher ratio of amine groups and obvious tendentiousness in protonation was successfully synthesized from ethylenediamine, acryloyl chloride and aziridine by five steps, in which the metal-organic framework (MOF) was employed as a catalyst for ring-open polycondensation (ROP). The structure and purity were confirmed by nuclear magnetic resonance hydrogen spectroscopy and high-performance liquid chromatography (HPLC) respectively. The HBPA displays more excellent performance than EDA and $\mathrm{KCl}$ widely applied in the oil field. After aging at $80^{\circ} \mathrm{C}$ and $180^{\circ} \mathrm{C}$, the $\mathrm{YP}$ of a slurry system containing $25 \mathrm{wt} \%$ bentonite and $2 \mathrm{wt} \%$ HBPA are just $8.5 \mathrm{~Pa}$ and $5.5 \mathrm{~Pa}$ (wt.\%: percentage of mass), respectively. The swelling lengths of 2 wt.\% HBPA are estimated to be $1.78 \mathrm{~mm}$, which falls by $70 \%$ compared with that of freshwater. Under a hot rolling aging temperature of $180^{\circ} \mathrm{C}$, the $\mathrm{HBPA}$ system demonstrates a significant inhibition with more than $85 \%$ shale cuttings recovery rate and is superior to conventional EDA and $\mathrm{KCl}$. Mechanism analysis further validates that the HBPA can help to increase the zeta potential.
\end{abstract}

\section{Keywords}

Water-Based Drilling Fluid, Inhibitors, Hyperbranched Polyamine, Metal Organic Framework Catalyst, Amine Groups 


\section{Introduction}

According to the complex and numerous chemical and physical variations present in the formation, normal inhibitors don't deliver satisfactory performances for preventing shale hydration swelling and dispersion in water-based drilling fluids [1] [2], and the existence of water sensitivity would produce a series of problems such as instability and collapse of the wellbore, bit balling, stuck pipe, etc [3] [4].

The linear-chain molecular structure is a much important factor that restricts the performance of the existing inhibitors [5]. Molecules adsorbed on the surface of the electronegative clay particles have absorbing groups with low density at either end and desorption takes place most easily when subjected to every downhole factor, resulting in a sharp decline in inhibitory action [6] [7] [8].

Compared with linear polymer, hyperbranched polymer, as a kind of quasi-spherical shape polymer with dominated branched structure, can introduce numerous absorbing groups at the end of the molecular chains by the functionalization and modification of end-groups, which was propitious for the molecular chain to the adsorption on the surface of clay [5]. Excluding terminal groups, the increase of absorbing groups along the chains could also enhance the adsorption capacity. The resulting molecular is adsorbed onto the negatively charged clay mineral and enters the interlayer space to tighten the crystalline layers of clay minerals, preventing shale hydration swelling [9].

In this study, a kind of hyperbranched polymer with a higher ratio of amine groups was designed and synthesized. Benefiting from this structure, primary amine, secondary amine and amide groups would produce protonated products in serious alkaline drilling fluids, which endow the molecule with strong adsorbability and thus help boost the inhibition performance of HBPA. Attributing to the characterization results of inhibitive properties, the as-synthesized HBPA significantly performances better than currently available $\mathrm{EDA}$ and $\mathrm{KCl}$ in bentonite inhibition test, linear swelling test and shale cuttings hot-rolling dispersion test. Besides, zeta potential measurements were carried out to investigate the inhibiting mechanism. Compared to EDA and $\mathrm{KCl}$, the HBPA system experiences the greatest drop and no charge reversal appears.

\section{Experimental}

\subsection{Materials}

Ethylenediamine (EDA, AR, >99\%): colorless or slightly yellow viscous liquid, melting point $8.5^{\circ} \mathrm{C}$, boiling point $116^{\circ} \mathrm{C}$, relative density 0.899 , belongs to alkaline material, soluble in water, ethanol, slightly soluble in ether.

Di-tert-butyl dicarbonate $\left(\mathrm{Boc}_{2} \mathrm{O},>98 \%\right)$ : a new type of amino protective agent, the product is a colorless crystal or colorless liquid, melting point $22^{\circ} \mathrm{C}$, boiling point $56^{\circ} \mathrm{C}$, relative density 0.950 , dissolved in tetrahydrofuran, trichloromethane and other organic solvents, slightly soluble in water.

Trifluoroacetic acid (TFA) (AR, >99\%): excellent solvent for organic reaction, melting point $-15.6^{\circ} \mathrm{C}$, boiling point $71.1^{\circ} \mathrm{C}$, relative density 1.5351 , used in this 
paper for the removal of BOC protective group.

Triethylamine (AR, >99\%): an organic compound, colorless oily liquid, melting point $-114.8^{\circ} \mathrm{C}$, boiling point $89.5^{\circ} \mathrm{C}$, relative density 0.728 , used as an acid-binding agent.

Citric acid monohydrate $(\mathrm{AR},>99 \%)$ : organic compound, melting point $-94^{\circ} \mathrm{C}$, boiling point $56^{\circ} \mathrm{C}$, relative density 0.791 , used in this paper for removing impurities of the product.

$\mathrm{KCl}$ : white crystal powder, melting point $770^{\circ} \mathrm{C}$, boiling point $1420^{\circ} \mathrm{C}$, relative density 1.98, was used as the control experiment of inhibition performance of synthetic hyperbranched polyamine (HBPA) (Figure 1).<smiles>C=CC(=O)C(=O)NCCNC(=O)OC(C)(C)C=CC(=O)NCCNC(=O)OC(C)(C)C</smiles>

(1)

(2)

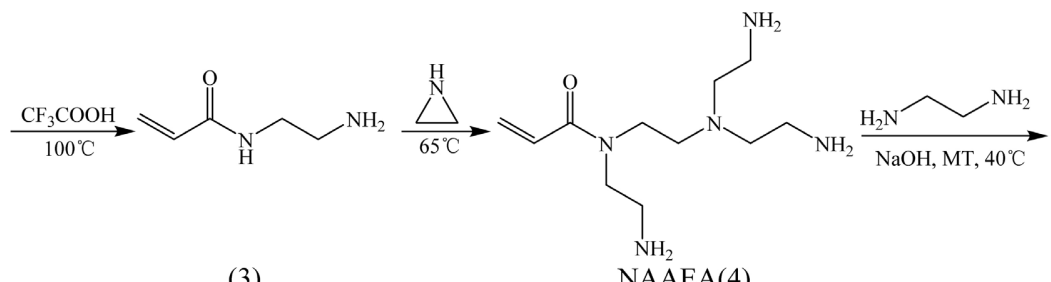<smiles>[R]CC[R](C)CC(=O)N(CCN)CCN(CCN)CCN</smiles>

Figure 1. Schematic diagram of synthesis of the HBPA.

Aziridine was prepared based on the relevant reference [10].

The Sodium bentonite (Na-bent) was a natural smectic aluminosilicate.

\subsection{Sample Preparation}

\subsubsection{Tert-Butyl (2-Aminoethyl)Carbamate (1)}

To a solution of EDA $(0.224 \mathrm{~mol}, 15 \mathrm{~mL})$ and tetrahydrofuran (THF) (75 mL) was added the di-tert-butyl dicarbonate $\left(\mathrm{Boc}_{2} \mathrm{O}\right)(0.04353 \mathrm{~mol}, 10 \mathrm{~mL})$ at $0{ }^{\circ} \mathrm{C}$ $5^{\circ} \mathrm{C}$. The reaction mixture was stirred at $25^{\circ} \mathrm{C}$ for $24 \mathrm{~h}$ and then yellow oily liquid (5.57 g, 80\%) was obtained through filtration, washing and concentration. ${ }^{1} \mathrm{H}$ NMR (400 MHz, $\left.\mathrm{CDCl}_{3}\right) \delta: 1.44\left(\mathrm{~s}, 9 \mathrm{H}, \mathrm{CH}_{3}\right), 1.53\left(\mathrm{~s}, 2 \mathrm{H}, \mathrm{NH}_{2}\right), 2.54$ - $2.56(\mathrm{~m}$, $\left.2 \mathrm{H}, \mathrm{N}-\mathrm{CH}_{2}\right), 3.41-3.43\left(\mathrm{~m}, 2 \mathrm{H}, \mathrm{CH}_{2}-\mathrm{N}\right), 6.75(\mathrm{~s}, 1 \mathrm{H}, \mathrm{NH})$.

\subsubsection{Tert-Butyl (2-Acrylamidoethyl)Carbamate (2)}

Acryloyl chloride $(4.5 \mathrm{mmol}, 0.41 \mathrm{~g})$ was added to a solution of 1 (4.5 mmol, $0.72 \mathrm{~g}$ ), triethylamine $(5.4 \mathrm{mmol}, 0.55 \mathrm{~g})$ and methylene chloride (DCM) (20 $\mathrm{mL}$ ), and the acryloyl chloride $(4.5 \mathrm{mmol}, 0.41 \mathrm{~g})$ dissolved in DCM (15 mL) was added slowly at $0^{\circ} \mathrm{C}-5^{\circ} \mathrm{C}$. The solution was stirred overnight and warmed to 
$25^{\circ} \mathrm{C}$ during this period. and then excess solvent was removed under vacuum. The residue was diluted with saturated sodium bicarbonate solution following extraction with $\mathrm{CH}_{2} \mathrm{Cl}_{2}$, then the combined solution was dried and concentrated to give $3(0.72 \mathrm{~g}, 75 \%)$ as a light-yellow powder. ${ }^{1} \mathrm{H}$ NMR (400 MHz, DMSO) $\delta$ : $1.37\left(\mathrm{~s}, 9 \mathrm{H}, \mathrm{CH}_{3}\right), 3.14\left(\mathrm{~s}, 4 \mathrm{H}, \mathrm{CH}_{2}-\mathrm{CH}_{2}\right), 5.60(\mathrm{~s}, 1 \mathrm{H}, \mathrm{CH}=\mathrm{C}), 6.07(\mathrm{~d}, 1 \mathrm{H}$, $\mathrm{CH}=\mathrm{C}), 6.12-6.26(\mathrm{~m}, 1 \mathrm{H}, \mathrm{C}=\mathrm{CH}), 6.81(\mathrm{~s}, 1 \mathrm{H}, \mathrm{NH}), 8.10(\mathrm{~s}, 1 \mathrm{H}, \mathrm{NH})$.

\subsubsection{N-(2-Aminoethyl)Acrylamide (3)}

TFA $(2.5 \mathrm{~mL})$ was added to a solution of $2(4.5 \mathrm{mmol}, 0.963 \mathrm{~g})$ and ethyl acetate $(10 \mathrm{~mL})$ at $0^{\circ} \mathrm{C}-5^{\circ} \mathrm{C}$. The solution was heated in an oil bath $\left(100^{\circ} \mathrm{C}\right)$ for $12 \mathrm{~h}$, and then the excess solvent was removed under vacuum. The remains were diluted with n-butanol $(15 \mathrm{~mL})$ and washed with saturated sodium carbonate solution. The yellow solution was concentrated to give $4(0.36 \mathrm{~g}, 70 \%) .{ }^{1} \mathrm{H}$ NMR (400 $\left.\mathrm{MHz}, \mathrm{CDCl}_{3}\right) \delta: 1.31\left(\mathrm{~s}, 2 \mathrm{H}, \mathrm{NH}_{2}\right), 2.52\left(\mathrm{~d}, 2 \mathrm{H}, \mathrm{CH}_{2}-\mathrm{N}\right), 3.37\left(\mathrm{~d}, 2 \mathrm{H}, \mathrm{N}-\mathrm{CH}_{2}\right)$, $5.61(\mathrm{~d}, 1 \mathrm{H}, \mathrm{CH}=\mathrm{C}), 6.11(\mathrm{~d}, 1 \mathrm{H}, \mathrm{CH}=\mathrm{C}), 6.23-6.25(\mathrm{~m}, 1 \mathrm{H}, \mathrm{C}=\mathrm{CH}), 8.44(\mathrm{~s}, 1 \mathrm{H}$, $\mathrm{NH})$.

\subsubsection{NAAEA (4)}

The aqueous solution with $3(4.5 \mathrm{mmoL}, 0.51 \mathrm{~g})$ and aziridine $(13.5 \mathrm{mmol}, 0.58$ g) were mixed, then the reaction mixture was stired at $65^{\circ} \mathrm{C}$ for $10 \mathrm{~h}$. the yellow liquid $5(0.90 \mathrm{~g}, 82 \%)$ was obtained by alkali treatment process and concentration. ${ }^{1} \mathrm{H}$ NMR (400 MHz, $\mathrm{CDCl}_{3}$ ) $\delta: 1.44\left(\mathrm{~s}, 6 \mathrm{H}, \mathrm{NH}_{2}\right), 2.55\left(\mathrm{~s}, 6 \mathrm{H}, \mathrm{N}-\mathrm{CH}_{2}\right), 2.78$ (s, $\left.4 \mathrm{H}, \mathrm{CH}_{2}-\mathrm{N}\right), 3.04\left(\mathrm{~d}, 2 \mathrm{H}, \mathrm{CH}_{2}-\mathrm{N}\right), 3.2-3.3\left(\mathrm{~m}, 2 \mathrm{H}, \mathrm{N}-\mathrm{CH}_{2}\right), 3.4(\mathrm{~s}, 2 \mathrm{H}$, $\left.\mathrm{N}-\mathrm{CH}_{2}\right), 3.83-3.85(\mathrm{~m}, 1 \mathrm{H}, \mathrm{CH}=\mathrm{C}), 3.99(\mathrm{~s}, 1 \mathrm{H}, \mathrm{CH}=\mathrm{C}), 4.97(\mathrm{~s}, 1 \mathrm{H}, \mathrm{C}=\mathrm{CH})$.

\subsubsection{Hyperbranched Amine Inhibitor (HBPA) (5)}

A suspension of $4(2.19 \mathrm{~g}, 9 \mathrm{mmol}), \mathrm{NaOH}(21 \mathrm{mg})$ and $\mathrm{EDA}(3 \mathrm{mmol}, 0.2 \mathrm{~mL})$ in methanol $(20 \mathrm{~mL})$ was stirred at $40^{\circ} \mathrm{C}$ for $6 \mathrm{~h}$ under a nitrogen atmosphere. Compound $6(1.88 \mathrm{~g}, 79 \%)$ was obtained as a light-yellow oil. ${ }^{1} \mathrm{H}$ NMR (400 $\left.\mathrm{MHz}, \mathrm{CDCl}_{3}\right) \delta: 1.10-1.15\left(\mathrm{~m}, 1 \mathrm{H}, \mathrm{CH}_{3}\right), 1.44\left(\mathrm{~s}, 6 \mathrm{H}, \mathrm{NH}_{2}\right), 2.54\left(\mathrm{~s}, 6 \mathrm{H}, \mathrm{N}-\mathrm{CH}_{2}\right)$, $2.59\left(\mathrm{~s}, 4 \mathrm{H}, \mathrm{CH}_{2}-\mathrm{N}\right), 2.68\left(\mathrm{~s}, 2 \mathrm{H}, \mathrm{N}-\mathrm{CH}_{2}\right), 2.78\left(\mathrm{~s}, 2 \mathrm{H}, \mathrm{CH}_{2}-\mathrm{N}\right), 3.22(\mathrm{~s}, 2 \mathrm{H}$, $\left.\mathrm{CH}_{2}-\mathrm{N}\right), 3.30\left(\mathrm{~d}, 2 \mathrm{H}, \mathrm{CH}_{2}-\mathrm{N}\right), 3.33(\mathrm{~s}, 1 \mathrm{H}, \mathrm{NH}), 3.45-3.49\left(\mathrm{~m}, 2 \mathrm{H}, \mathrm{N}=\mathrm{CH}_{2}\right)$.

\subsection{Characterization}

\section{${ }^{1} \mathrm{H}-\mathrm{NMR}$ and HPLC Analysis}

The product of each step was investigated by use of nuclear magnetic resonance hydrogen spectroscopy with tetramethylsilane as an internal reference, and the measurement was performed on an advanced -400 spectrometer at $25^{\circ} \mathrm{C}$. In order to further verify the rationality and reliability of these strategies in the synthesis of HBPA, High-Performance Liquid Chromatography (HPLC) was used to characterize the high purity of the target compound.

\subsection{Inhibition Property Evaluation}

\subsubsection{Bentonite Inhibition Test}

The incorporation of highly active drilled solids into a drilling fluid is simulated in the technique, which closely resembles the process of drilling in water-sensitivity 
soil. A solution of $5 \mathrm{wt} . \%$ bentonite ( $20 \mathrm{~g})$ and a certain concentration of shale inhibitors dissolved in $400 \mathrm{~mL}$ freshwater was stirred for about $30 \mathrm{~min}$, then the mixture was hot rolled for $16 \mathrm{~h}$ at different temperatures. After cooling to $25^{\circ} \mathrm{C}$, their rheology was measured. Then, added an equal amount of bentonite and the operation was the same as the previous. This process repeated until the data was unreadable resulting from the excessive viscosity of the sample.

\subsubsection{Linear Swelling Test}

The impact of inhibitor on shale cuttings exposed to the water-based drilling fluid can be assessed by linear swelling measurements which are carried out at $25^{\circ} \mathrm{C}$. A large linear swelling rate corresponds to fairly strong hydration reactivity. Firstly, bentonite powder ( $10 \mathrm{~g}$ ) was compressed into bentonite pellets. Then the swelling heights of pellets soaked in a certain concentration of a solution containing various inhibitors were investigated.

\subsubsection{Shale Cuttings Hot-Rolling Dispersion Test}

This method is designed to evaluate exactly the ability of inhibitors to prevent shale hydration swelling and dispersion by determining the influence of inhibitors on determining the effect of an inhibitor on the structural integrity of sized cuttings at elevated temperature. Added a $350 \mathrm{~mL}$ solution containing $50 \mathrm{~g}$ shale cuttings and various concentrations of inhibitors to the aging jars for hot rolling aging for $16 \mathrm{~h}$, then, the remaining shale cuttings of a certain size were screened with a 40 mesh sieve. After washing and drying to a constant mass, the recovery of cuttings can be calculated according to the formula below.

$$
\text { Recovery }=\frac{\text { The constant mass }}{50} \times 100 \%
$$

\subsection{Inhibition Mechanism Analysis}

\section{Zeta Potential Measurement}

For clay particles, the trend of swelling and dispersion weakens with the absolute value of negative zeta potential decreasing. Normally, this test is used to evaluate the stability of clay dispersions via the changing trends of electrokinetic properties for bentonite affected by inhibitors. A series of bentonite suspensions of the same concentration ( 4 wt.\%) were employed as base slurry samples and kept stirring for $24 \mathrm{~h}$. Then adding various concentrations of inhibitors to these slurry samples to continue to stir for another $24 \mathrm{~h}$, the supernatant was diluted to zeta potential determination.

\section{Results and Discussion}

\subsection{Characterization}

The polybasic primary amine structure of HBPA was confirmed by ${ }^{1} \mathrm{H}$ NMR analysis, which spectra were shown in Figure 2(a). The ${ }^{1} \mathrm{H}$ NMR spectrum confirms the presence of primary amine in this HBPA structure with the chemical shift peaks of $1.5 \mathrm{ppm}$. It can be observed that the spectra have characteristic shifts of methylene groups, corresponding to seven kinds of protons in methy- 
lene under different chemical environments on this sample. There is chemical shift peaks at $3.32 \mathrm{ppm}$, attributed to protons of NHgroups. Figure 2(b) is the typical analytical HPLC (High-Performance Liquid Chromatography) chromatograms for the prepared HBPA. The results indicated that the contents of two components in the product were $72.1 \%$ and $27.9 \%$, respectively.

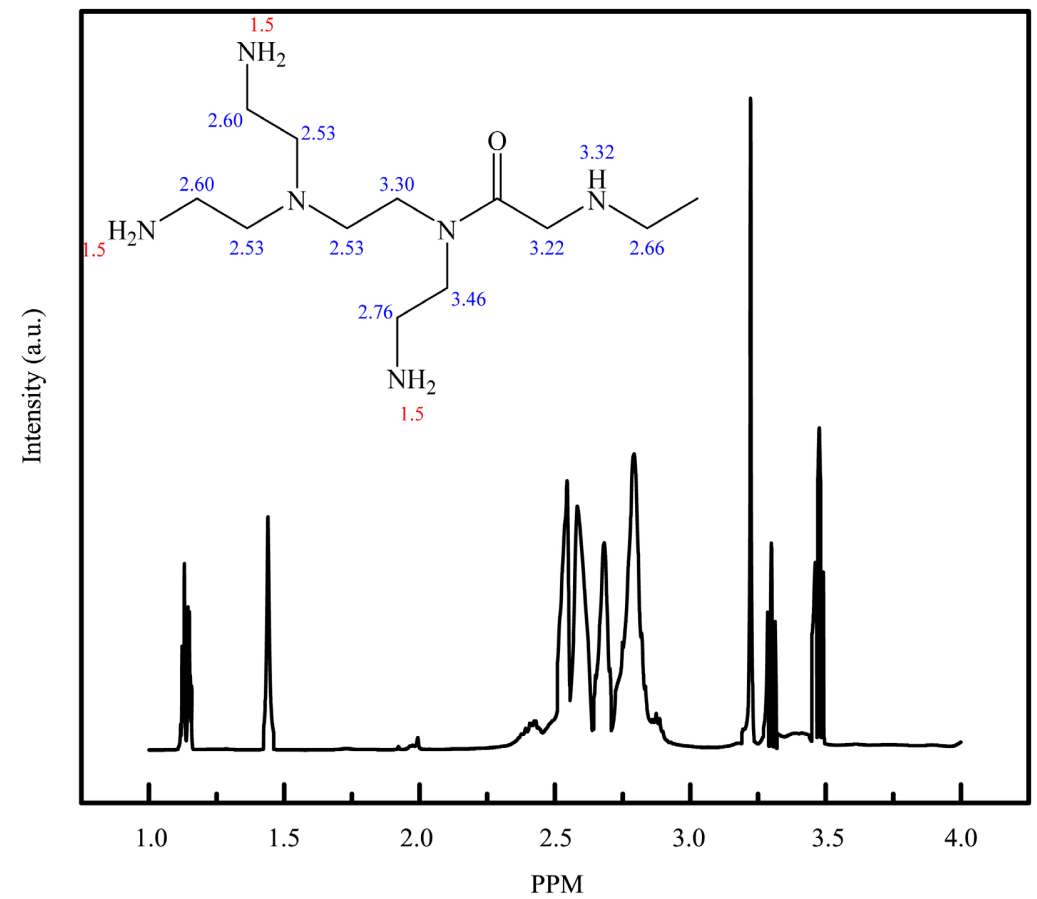

(a)

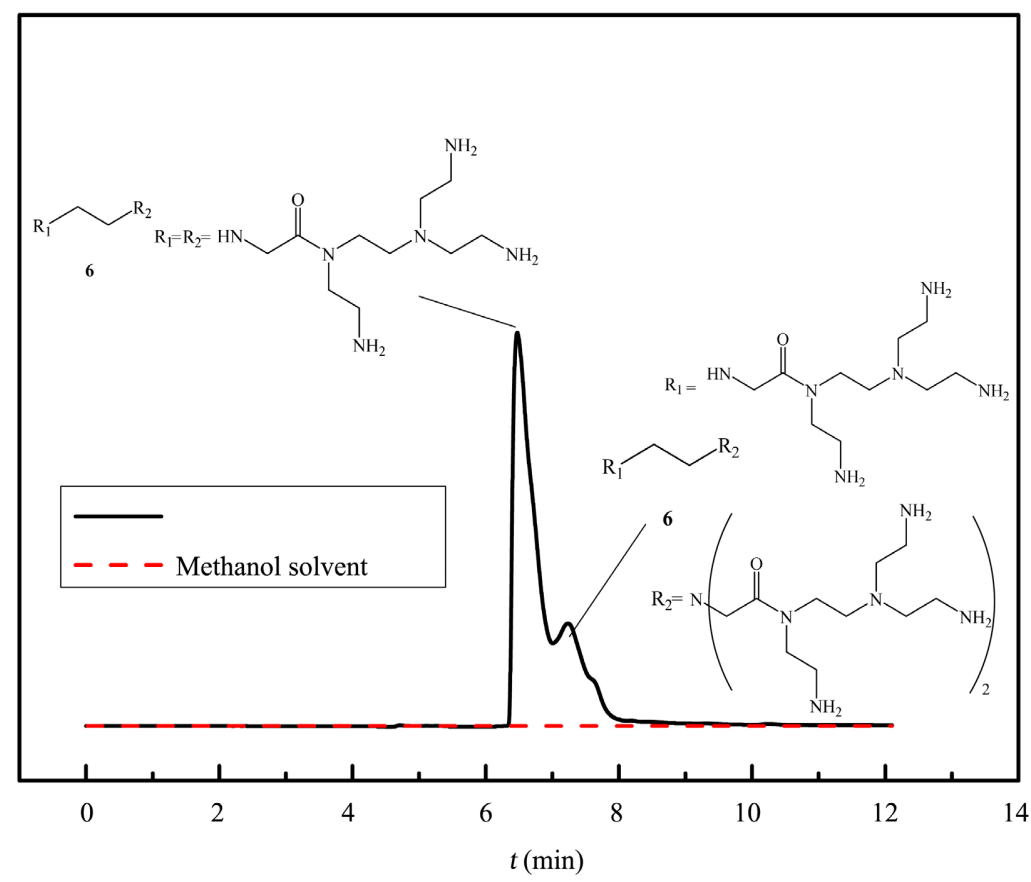

(b)

Figure 2. (a) ${ }^{1} \mathrm{H}-\mathrm{NMR}$ of the HBPA; (b) The HPLC chromatogram of the HBPA. 


\subsection{Inhibitive Properties Evaluation}

\subsubsection{Bentonite Inhibition Test}

The ability of the inhibitor to prevent shale hydration swelling can be detected by the changing rules of yield points for bentonite slurries with various concentrations [11] [12] [13]. The evaluation results of the bentonite inhibition test were shown in Figure 3. When increasing the addition of bentonite under the absence of inhibitors, the YP shows a rapid increase, and the value quickly becomes unmeasurable as the additive content of bentonite reaches $15 \%$ of the total drilling fluid mass, suggesting the swelling behavior of bentonite [14]. By comparison, the increasing of YP of a slurry system containing different inhibitors develops slowly initially, and the value changes abruptly under higher bentonite concentration. Encouraging, compared with the two conventional inhibitors, the swelling of bentonite is inhibited by HBPA ( 2 wt.\%) to maximum. To further evaluate the inhibition effect of these serious additives at elevated temperatures, trends in yield points for bentonite slurries with various inhibitors were examined under the conditions of $180^{\circ} \mathrm{C}$. Figure 3 reveals that the $2 \mathrm{wt} . \%$

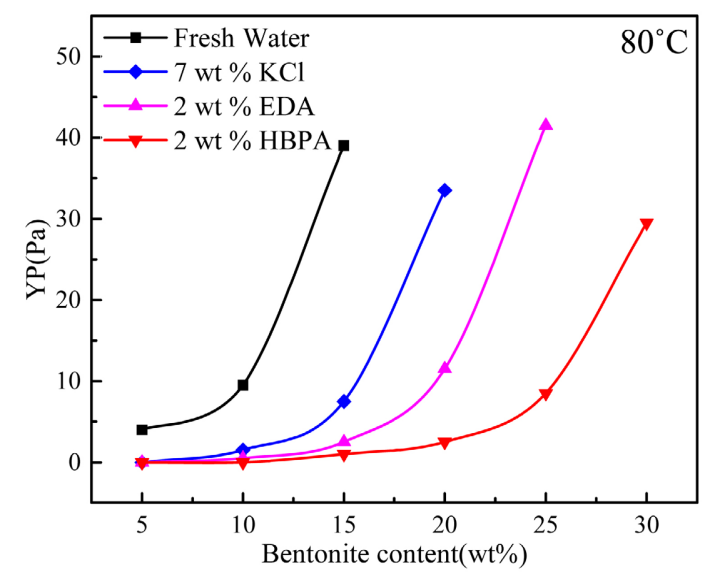

(a)

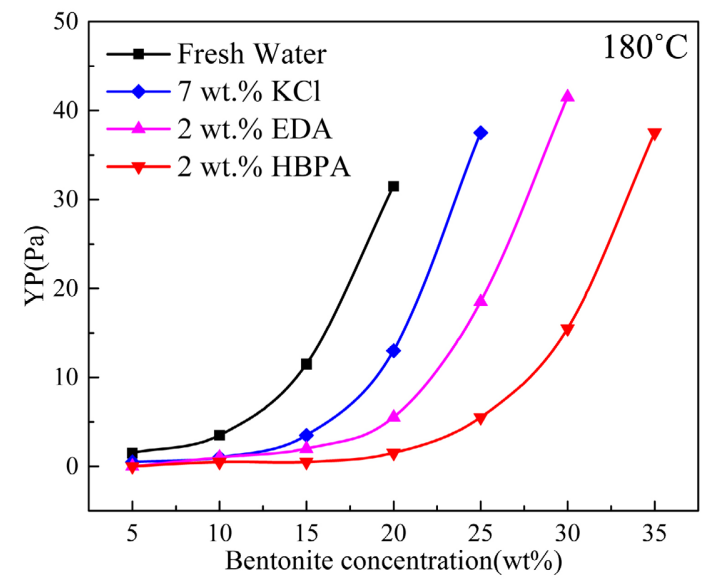

(b)

Figure 3. Variation of yield value with bentonite concentration in various inhibitor Solutions at $80^{\circ} \mathrm{C}$ (a) and $180^{\circ} \mathrm{C}$ (b). ${ }^{*}$ apparatus: Model 900 viscometer, the data was measured at $25^{\circ} \mathrm{C}$. 
HBPA displays superior performance, and the order was 2 wt.\% HBPA > 2 wt.\% EDA $>7$ wt.\% $\mathrm{KCl}$ for the properties of inhibition.

\subsubsection{Linear Swelling Test}

Linear swelling test can specifically estimate the swelling degree of rock samples with drilling fluids [15], especially for highly reactive shale formation containing abundant swelling clays [16] [17] [18]. The inhibitive durability of the prepared HBPA inhibitor was detected and the results were shown in Figure 4. For comparison, the $\mathrm{EDA}, \mathrm{KCl}$ and freshwater systems were also tested under identical conditions. During the initial test phase, the swelling and hydration of bentonite pellet increase rapidly, and then a plateau is reached where the linear swelling lengths turn to be relatively stable. Measurement results suggest that the swelling lengths of 0.5 wt.\% EDA, 1 wt.\% EDA, 2 wt.\% EDA, 7 wt.\% KCl, 0.5 wt.\% HBPA, 1 wt.\% HBPA, 2 wt.\% HBPA are estimated to be 3.39, 2.51, 2.09, 2.94, 2.20, 1.86 and $1.78 \mathrm{~mm}$, respectively. Obviously, compared with $\mathrm{EDA}$ and $\mathrm{KCl}$ systems, the HBPA has resulted in the biggest drops in the expandability of bentonite [19].

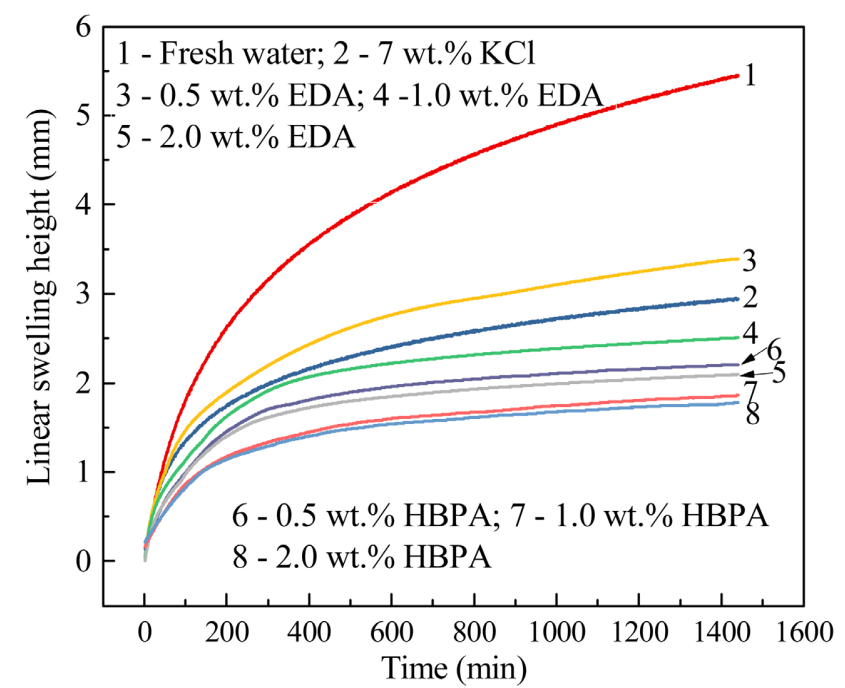

Figure 4. Linear swelling lengths of bentonite pellets in various inhibitor systems.

Ultimately, the excellent performance of the HBPA to prevent shale hydration swelling owes a great deal to the inherent characteristics [20] [21] [22] [23]: 1) the relatively more amine groups can evenly adsorb on the clay to render the clay surface more hydrophobic and promote the release of interlayer water. 2) Hyperbranched polymer, as a kind of quasi-spherical shape polymer with dominated branched structure, can introduce numerous absorbing groups at the end of the molecular chains by the functionalization and modification of end-groups.

\subsubsection{Rolling Recovery Tests}

According to the test standards released by ISO 10416: 2008 Petroleum and Natural Gas Industries Industries Drilling Fluids Laboratory Testing, shale recovery is the most used approach for further evaluating the inhibiting perfor- 
mance of bentonite [24] [25]. By comparison of the results in Table 1 and Figure 5 , it can be clearly seen that the shale recovery rate is extremely low in fresh water at various hot-rolling temperatures, declining from $49.68 \%$ for $80^{\circ} \mathrm{C}$ to $34.68 \%$ for $120^{\circ} \mathrm{C}, 29.50 \%$ for $160^{\circ} \mathrm{C}$ and $27.31 \%$ for $180^{\circ} \mathrm{C}$, respectively, exemplifying the hydration tendency of shale cuttings [26]. Compared to those under freshwater, the shale recovery rates which are treated by inhibitors are all satisfactory under the lower temperature of $80^{\circ} \mathrm{C}$. The recovery rates are with respect to the order of $7 \mathrm{wt} . \% \mathrm{KCl}<5 \mathrm{wt} . \% \mathrm{KCl}<0.5 \mathrm{wt} . \% \mathrm{EDA}<1$ wt.\% $\mathrm{EDA}<2$ wt.\% EDA $<0.5$ wt.\% HBPA $<1$ wt.\% HBPA $<2$ wt.\% HBPA. At elevated temperatures, maintaining the integrity of shale becomes more difficult. The swelling and hydration of shale are strongly accelerated, and the adsorption of inhibitors on the clay surface, on the other hand, will weaken. These defects could cause rock fragments to separate from the wellbore wall during the drilling [27]. From Figure 5 and Table 1, although the recovery rates for all inhibitors decline as

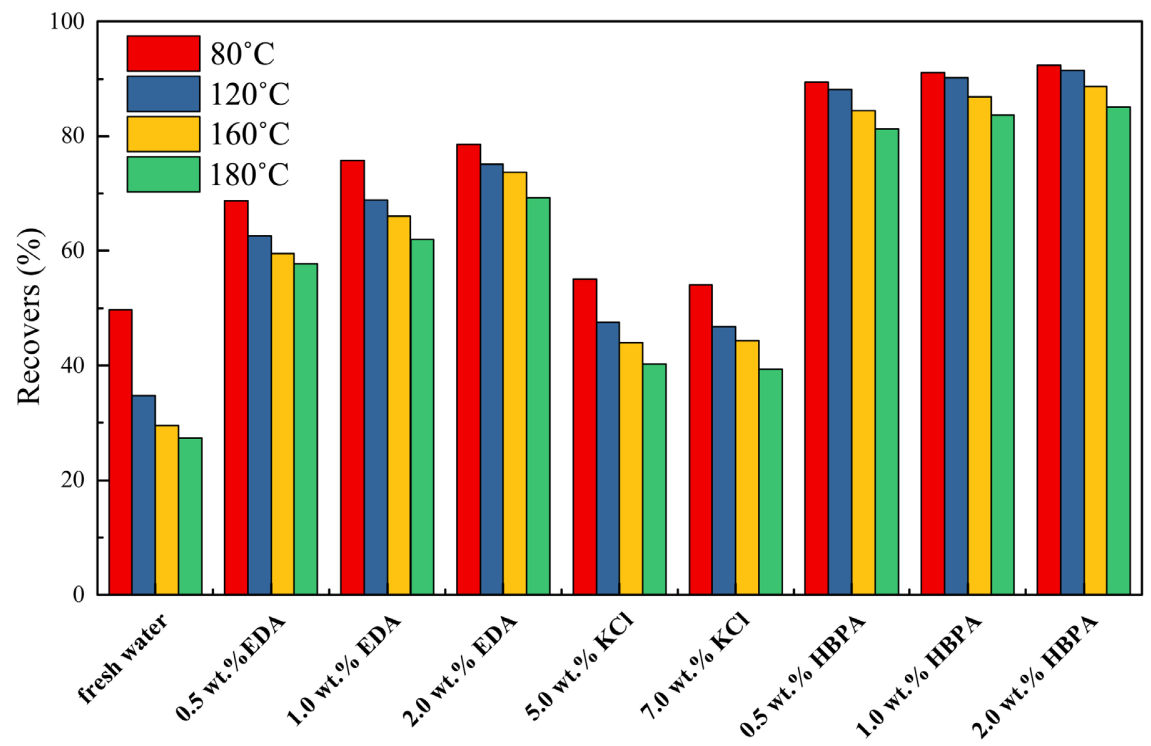

Figure 5. Shale recovery ratios of various inhibitors after hot rolling at different temperatures for $16 \mathrm{~h}$.

Table 1. Shale cuttings recoveries of different inhibitor systems at different rolling temperatures.

\begin{tabular}{|c|c|c|c|c|c|c|c|c|c|}
\hline \multirow{3}{*}{ Temperature } & \multicolumn{9}{|c|}{ Inhibitors } \\
\hline & \multirow{2}{*}{$\begin{array}{l}\text { Fresh } \\
\text { Water }\end{array}$} & \multicolumn{3}{|c|}{ EDA } & \multicolumn{2}{|c|}{$\mathrm{KCl}$} & \multicolumn{3}{|c|}{ HBPA } \\
\hline & & 0.5 wt. $\%$ & 1.0 wt. $\%$ & 2.0 wt. $\%$ & 5.0 wt.\% & 7.0 wt.\% & 0.5 wt. $\%$ & 1.0 wt.\% & 2.0 wt. $\%$ \\
\hline $80^{\circ} \mathrm{C}$ & $49.68 \%$ & $68.66 \%$ & $75.80 \%$ & $78.60 \%$ & $55.00 \%$ & $54.00 \%$ & $89.41 \%$ & $91.13 \%$ & $92.26 \%$ \\
\hline $120^{\circ} \mathrm{C}$ & $34.68 \%$ & $62.56 \%$ & $68.86 \%$ & $75.06 \%$ & $47.50 \%$ & $46.72 \%$ & $88.10 \%$ & $90.21 \%$ & $91.48 \%$ \\
\hline $160^{\circ} \mathrm{C}$ & $29.50 \%$ & $59.50 \%$ & $66.00 \%$ & $73.66 \%$ & $43.90 \%$ & $44.30 \%$ & $84.52 \%$ & $86.90 \%$ & $88.61 \%$ \\
\hline $180^{\circ} \mathrm{C}$ & $27.31 \%$ & $57.72 \%$ & $62.04 \%$ & $69.32 \%$ & $40.20 \%$ & $39.32 \%$ & $81.30 \%$ & $83.71 \%$ & $85.12 \%$ \\
\hline
\end{tabular}

${ }^{*}$ Rolling time: $16 \mathrm{~h}$. 
temperature rises, among which the 2 wt.\% HBPA shows the smallest drop, only $0.8 \%$ for $120^{\circ} \mathrm{C}$ and $3.9 \%$ for $160^{\circ} \mathrm{C}$. Besides, According to the data under a high temperature of $180^{\circ} \mathrm{C}$, the HBPA system remains ahead of its rivals in shale recovery with a satisfactory value of $85.12 \%$, further confirming the excellent inhibitive and heat-resistance [28]. The above mentioned together could elucidate the prepared HBPA could effectively inhibit shale dispersion during drilling.

\subsection{Mechanism Analysis}

\section{Zeta Potential Test}

Electrokinetic properties of clay were performed to reveal the interactions between HBPA and clay particles, and the zeta potential pattern was displayed in Figure 6, with $\mathrm{EDA}$ and $\mathrm{KCl}$ inhibitor as reference. Commonly, the bentonite particle is a negative charge surface due to isomorphic replacements of ions in layers [29] [30]. The highly negative zeta potential of clay particles represents the enhanced shale hydration swelling and dispersion. As shown in Figure 6, the zeta potential value of sodium bentonite-based slurry is about $-34 \mathrm{mV}$, implying higher discursiveness [31] [32]. Due to the diffuse electric double layer suppression by metal ions, that value decreases with the addition of $\mathrm{KCl}$. As the concentration reaches $1.5 \mathrm{wt}$ \%, the HBPA system experiences the greatest rise from $-34 \mathrm{mV}$ to $-12.8 \mathrm{mV}$, about $21.2 \mathrm{mV}$, then a plateau is reached and no charge reversal appears during the whole concentration range, indicating that the adsorption of HBPA onto the clay surface reached saturation. Though the changing trend of the EDA is similar to HBPA, the latter can increase the zeta potential more positively than EDA.

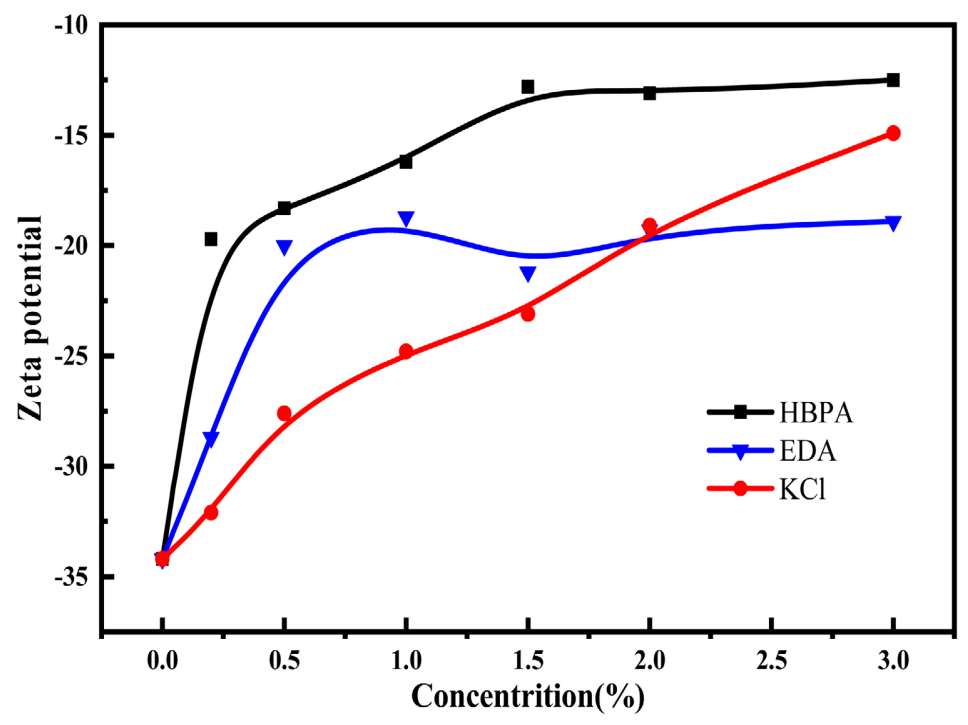

Figure 6. Zeta potential variation of different inhibitors with concentrations.

Amine group would be protonated when dissolved in an aqueous solution [33], The protonated ammonium ions neutralized the negatively charged clay surface and resulted in the increase of zeta potential. Besides, attributing to the 
alkalescent property of the amine, no charge reversal was observed throughout the testing stage. Benefiting from this hyperbranched polymer with a higher ratio of amine groups, the HBPA increased the zeta potential to a higher degree than EDA and KCL, indicating the excellent performance to prevent shale hydration swelling and dispersion.

\section{Conclusion}

Hyperbranched polyamine (HBPA) inhibitor with a higher ratio of amine groups and obvious tendentiousness in protonation used as an effective shale inhibitor in water-based drilling fluids has been developed, and a kind of MOFs was chosen as ring-open polycondensation catalyst for this process. Compared with the traditional inhibitors, the HBPA inhibitor shows significantly inhibitive properties which can meet the demands of controlling and mitigating the shale hydrating and dispersing. In bentonite inhibition evaluation, the swelling of clay is inhibited by HBPA to maximum, and the same is true at up to $180^{\circ} \mathrm{C}$ conditions. The HBPA also exhibits the lowest linear swelling lengths of $1.78 \mathrm{~mm}$. Meanwhile, the shale recovery rates of HBPA for $16 \mathrm{~h}$ reach $92.26 \%, 91.48 \%$, $88.61 \%$ and $85.12 \%$ for $80^{\circ} \mathrm{C}, 120^{\circ} \mathrm{C}, 160^{\circ} \mathrm{C}$ and $180^{\circ} \mathrm{C}$, respectively. Further, the validity of test results was verified by analyzing the inhibiting mechanism. In a conclusion, the prepared HBPA can effectively reduce shale hydration and dispersion and apply to high-temperature wells application.

\section{Conflicts of Interest}

The authors declare no conflicts of interest regarding the publication of this paper.

\section{References}

[1] Gholami, R., Elochukwu, H., Fakhari, N. and Sarmadivaleh, M. (2018) A Review on Borehole Instability in Active Shale Formations: Interactions, Mechanisms and Inhibitors. Earth-Science Reviews, 177, 2-13.

https://doi.org/10.1016/j.earscirev.2017.11.002

[2] Young, S. and Iskander, G.R. (2006) Drilling Performance and Environmental Compliance-Resolution of Both with a Unique Water Based Fluid. In: SPE/IADC Indian Drilling Technology Conference and Exhibition, Society of Petroleum Engineers, Mumbai, 11. https://doi.org/10.2118/103967-MS

[3] Ahmed, H.M., Kamal, M.S. and Al-Harthi, M. (2019) Polymeric and Low Molecular Weight Shale Inhibitors: A Review. Fuel, 251, 187-217.

https://doi.org/10.1016/j.fuel.2019.04.038

[4] Ma, J., Yu, P., Xia, B., An, Y. and Wang, Z. (2019) Synthesis of a Biodegradable and Environmentally Friendly Shale Inhibitor Based on Chitosan-Grafted 1-Arginine for Wellbore Stability and the Mechanism Study. ACS Applied Bio Materials, 2, 4303-4315. https://doi.org/10.1021/acsabm.9b00566

[5] Cao, X., Li, Z., Song, X., Cui, X., Cao, P., Liu, H., Cheng, F. and Chen, Y. (2008) Core-Shell Type Multiarm Star Poly ( $\varepsilon$-caprolactone) with High Molecular Weight Hyperbranched Polyethylenimine as Core: Synthesis, Characterization and Encap- 
sulation Properties. European Polymer Journal, 44, 1060-1070.

https://doi.org/10.1016/j.eurpolymj.2008.01.035

[6] Ferreira, C.C., Teixeira, G.T., Lachter, E.R. and Nascimento, R.S.V. (2016) Partially Hydrophobized Hyperbranched Polyglycerols as Non-Ionic Reactive Shale Inhibitors for Water-Based Drilling Fluids. Applied Clay Science, 132-133, 122-132. https://doi.org/10.1016/j.clay.2016.05.025

[7] Xie, G., Xiao, Y., Deng, M., Luo, Y. and Luo, P. (2020) Low Molecular Weight Branched Polyamine as a Clay Swelling Inhibitor and Its Inhibition Mechanism: Experiment and Density Functional Theory Simulation. Energy \& Fuels, 34, 2169-2177. https://doi.org/10.1021/acs.energyfuels.9b04003

[8] Ashoori, S., Abdideh, M. and Alavi, A. (2015) 3D Geostatistical Modelling and Uncertainty Analysis of Clay Minerals Distribution in Reservoir Rocks. Geocarto International, 31, 241-255. https://doi.org/10.1080/10106049.2015.1047413

[9] Liu, Y., Xu, L., Liu, J., Liu, X., Chen, C., Li, G. and Meng, Y. (2016) Graphene Oxides Cross-Linked with Hyperbranched Polyethylenimines: Preparation, Characterization and Their Potential as Recyclable and Highly Efficient Adsorption Materials for Lead(II) Ions. Chemical Engineering Journal, 285, 698-708. https://doi.org/10.1016/j.cej.2015.10.047

[10] Wei, Y.Y. and Shao, Y. (2002) An Improved Synthesis of Pentaerythrityl Tetramine. Energetic Materials, 10, 49-52.

[11] Lei, M., Huang, W., Sun, J., Shao, Z., Duan, W., Wu, T. and Wang, Y. (2020) Synthesis, Characterization, and Performance of Carboxymethyl Chitosan with Different Molecular Weight as Additive in Water-Based Drilling Fluid. Journal of Molecular Liquids, 310, Article ID: 113135. https://doi.org/10.1016/j.molliq.2020.113135

[12] Leite, R.S., Dantas, A.P.T. and Amorim, L.V. (2016) Influence of Clay Swelling Inhibitor in Filtration Properties of Water-Based Drilling Fluids. Materials Science Forum, 869, 1018-1022. https://doi.org/10.4028/www.scientific.net/MSF.869.1018

[13] Lv, K., Huang, X., Li, H., Sun, J., Du, W. and Li, M. (2020) Modified Biosurfactant Cationic Alkyl Polyglycoside as an Effective Additive for Inhibition of Highly Reactive Shale. Energy \& Fuels, 34, 1680-1687. https://doi.org/10.1021/acs.energyfuels.9b04131

[14] Bilgili, F., Koçak, E., Bulut, Ü. and Sualp, M.N. (2016) How Did the US Economy React to Shale Gas Production Revolution? An Advanced Time Series Approach. Energy, 116, 963-977. https://doi.org/10.1016/j.energy.2016.10.056

[15] Zhong, H., Qiu, Z., Zhang, D., Tang, Z., Huang, W. and Wang, W. (2016) Inhibiting Shale Hydration and Dispersion with Amine-Terminated Polyamidoamine Dendrimers. Journal of Natural Gas Science and Engineering, 28, 52-60. https://doi.org/10.1016/j.jngse.2015.11.029

[16] Khodja, M., Canselier, J.P., Bergaya, F., Fourar, K., Khodja, M., Cohaut, N. and Benmounah, A. (2010) Shale Problems and Water-Based Drilling Fluid Optimisation in the Hassi Messaoud Algerian Oil Field. Applied Clay Science, 49, 383-393. https://doi.org/10.1016/j.clay.2010.06.008

[17] Gomez, S.L. and Patel, A. (2013) Shale Inhibition: What Works? In: SPE International Symposium on Oilfield Chemistry, Society of Petroleum Engineers, The Woodlands, 11. https://doi.org/10.2118/164108-MS

[18] Tian, C., Fu, S., Habibi, Y. and Lucia, L.A. (2014) Polymerization Topochemistry of Cellulose Nanocrystals: A Function of Surface Dehydration Control. Langmuir, 30, 14670-14679. https://doi.org/10.1021/la503990u 
[19] Wang, L.L., Zhang, G.Q., Hallais, S., Tanguy, A. and Yang, D.S. (2017) Swelling of Shales: A Multiscale Experimental Investigation. Energy \& Fuels, 31, 10442-10451. https://doi.org/10.1021/acs.energyfuels.7b01223

[20] Zhong, H., Qiu, Z., Huang, W. and Cao, J. (2011) Shale Inhibitive Properties of Polyether Diamine in Water-Based Drilling Fluid. Journal of Petroleum Science and Engineering, 78, 510-515. https://doi.org/10.1016/j.petrol.2011.06.003

[21] Gomez, S., Ke, M. and Patel, A. (2015) Selection and Application of Organic Clay Inhibitors for Completion Fluids. In: SPE International Symposium on Oilfield Chemistry, Society of Petroleum Engineers, The Woodlands, 12. https://doi.org/10.2118/173731-MS

[22] An, Y., Jiang, G., Ren, Y., Zhang, L., Qi, Y. and Ge, Q. (2015) An Environmental Friendly and Biodegradable Shale Inhibitor Based on Chitosan Quaternary Ammonium Salt. Journal of Petroleum Science and Engineering, 135, 253-260. https://doi.org/10.1016/j.petrol.2015.09.005

[23] Mathumba, P., Kuvarega, A.T., Dlamini, L.N. and Malinga, S.P. (2017) Synthesis and Characterisation of Titanium Dioxide Nanoparticles Prepared within Hyperbranched Polyethylenimine Polymer Template Using a Modified Sol-Gel Method. Materials Letters, 195, 172-177. https://doi.org/10.1016/j.matlet.2017.02.108

[24] Wang, Y., Liu, X., Liang, L. and Xiong, J. (2020) Experimental Study on the Damage of Organic-Rich Shale during Water-Shale Interaction. Journal of Natural Gas Science and Engineering, 74, Article ID: 103103. https://doi.org/10.1016/j.jngse.2019.103103

[25] Xie, G., Luo, P., Deng, M., Su, J., Wang, Z., Gong, R., Xie, J., Deng, S. and Duan, Q. (2017) Investigation of the Inhibition Mechanism of the Number of Primary Amine Groups of Alkylamines on the Swelling of Bentonite. Applied Clay Science, 136, 43-50. https://doi.org/10.1016/j.clay.2016.11.005

[26] Shi, X., Wang, L., Guo, J., Su, Q. and Zhuo, X. (2019) Effects of Inhibitor KCl on Shale Expansibility and Mechanical Properties. Petroleum, 5, 407-412. https://doi.org/10.1016/j.petlm.2018.12.005

[27] Liu, X., Zeng, W., Liang, L. and Xiong, J. (2016) Experimental Study on Hydration Damage Mechanism of Shale from the Longmaxi Formation in Southern Sichuan Basin, China. Petroleum, 2, 54-60. https://doi.org/10.1016/j.petlm.2016.01.002

[28] Zhang, S., Sheng, J.J. and Qiu, Z. (2016) Maintaining Shale Stability Using Polyether Amine While Preventing Polyether Amine Intercalation. Applied Clay Science, 132-133, 635-640. https://doi.org/10.1016/j.clay.2016.08.015

[29] Zheng, L., Su, G., Li, Z., Peng, R., Wang, L., Wei, P. and Han, S. (2018) The Wellbore Instability Control Mechanism of Fuzzy Ball Drilling Fluids for Coal Bed Methane Wells via Bonding Formation. Journal of Natural Gas Science and Engineering, 56, 107-120. https://doi.org/10.1016/j.jngse.2018.05.008

[30] Li, J., Qiu, Z., Zhong, H., Zhao, X. and Huang, W. (2020) Analysis of Chemo-PoroThermo-Mechanical Effects on Wellbore. Journal of Energy Resources Technology, 142, 1-29. https://doi.org/10.1115/1.4047460

[31] Yuan, J., Luo, D. and Feng, L. (2015) A Review of the Technical and Economic Evaluation Techniques for Shale Gas Development. Applied Energy, 148, 49-65. https://doi.org/10.1016/j.apenergy.2015.03.040

[32] Zheng, L., Kong, L., Cao, Y., Wang, H., Han, Z. and He, X. (2010) The Mechanism for Fuzzy-Ball Working Fluids for Controlling \& Killing Lost Circulation. Chinese Science Bulletin, 55, 4074-4082. https://doi.org/10.1007/s11434-010-3202-8 
[33] Wang, L., Liu, S., Wang, T. and Sun, D. (2011) Effect of Poly(oxypropylene)diamine Adsorption on Hydration and Dispersion of Montmorillonite Particles in Aqueous Solution. Colloids and Surfaces A: Physicochemical and Engineering Aspects, 381, 41-47. https://doi.org/10.1007/s11434-010-3202-8 